\title{
Association of PD-L1 and ZEB-1 expression patterns with clinicopathological characteristics and prognosis in oral squamous cell carcinoma
}

\author{
NATSUMI TAKAMARU, NAOYUKI FUKUDA, KAZUYA AKITA, KEIKO KUDOH and YOUJI MIYAMOTO \\ Department of Oral Surgery, Institute of Biomedical Sciences, \\ Tokushima University Graduate School, Tokushima 770-8504, Japan
}

Received September 29, 2021; Accepted December 13, 2021

DOI: $10.3892 / \mathrm{ol} .2022 .13195$

\begin{abstract}
Programmed cell death-1 (PD-1) and its ligand programmed cell death 1 ligand 1 (PD-L1) are immune checkpoint inhibitors that play an important role in the host immune avoidance mechanism of tumors. The relationship between PD-L1 expression and malignancy has been reported in various types of cancer, such as lung and gastric cancer. In addition, epithelial-mesenchymal transition (EMT) of cancer cells is deeply involved in the invasion and metastasis of cancer. It has been reported that zinc finger E-box binding homeobox 1 (ZEB-1), an EMT inducer, contributes to metastasis in pancreatic and colon cancer. The present study aimed to investigate the relationship between the expression patterns of two markers, PD-L1 and ZEB-1, and clinicopathological characteristics and prognosis of oral squamous cell carcinoma (OSCC). Biopsy or surgical excision specimens from 169 patients with OSCC were used in the present study. Immunohistochemical staining with monoclonal anti-PD-L1 antibody and anti-ZEB-1 antibody was conducted. Cases with $>1 \%$ tumor cells positive for PD-L1 and those with $>10 \%$ tumor cells positive for ZEB-1 were considered positive, respectively. The findings revealed that individual expression of PD-L1 and ZEB-1 in OSCC was not associated with tumor size, degree of differentiation or Yamamoto-Kohama invasion
\end{abstract}

Correspondence to: Dr Naoyuki Fukuda, Department of Oral Surgery, Institute of Biomedical Sciences, Tokushima University Graduate School, 3-18-15 Kuramoto-cho, Tokushima 770-8504, Japan

E-mail: naoyukifukuda@tokushima-u.ac.jp

Abbreviations: PD-1, programmed cell death 1; PD-L1, programmed cell death 1 ligand 1; ZEB-1, zinc finger E-box binding homeobox 1; EMT, epithelial-to-mesenchymal transition; ESCC, esophageal squamous cell carcinoma; OSCC, oral squamous cell carcinoma; YK classification, Yamamoto-Kohama classification; $\mathrm{HR}$, hazard ratio; CI, confidence interval

Key words: OSCC, PD-L1, ZEB-1, prognosis, overall survival, EMT, metastasis pattern classification. However, co-expression of PD-L1 and ZEB-1 was associated with higher cervical lymph node metastasis and a lower survival rate. In conclusion, the results of the present study indicated that co-expression of PD-L1 and ZEB-1 could serve as a potential marker for the prognosis of patients with OSCC.

\section{Introduction}

Neck and distant metastases are crucial prognostic factors in the treatment of oral cancer. Prediction of metastases by identifying prognostic markers could contribute towards the management and treatment of oral cancer; however, to date, no such prognostic markers have been identified (1).

Programmed cell death 1 (PD-1), which is expressed on the surface of activated $\mathrm{T}$ cells in healthy conditions, regulates unnecessary or heightened immune responses, including self-protective responses. Upon binding to a ligand, it negatively regulates the signal transduction through an antigen receptor. The PD-1 pathway is the main immune regulatory switch in cancer cells to escape the T-cell immune surveillance system (2). Despite its expression in a few normal tissues, programmed cell death 1 ligand 1 (PD-L1) is overexpressed in numerous cancer cells since it suppresses T-cell activity (2). Reportedly, high PD-L1 expression in cancer cells leads to a poor prognosis in various types of cancer, such as renal cell, hepatocellular, ovarian and non-small cell lung cancer (3-6).

Zinc finger E-box binding homeobox 1 (ZEB-1), also known as dEF1, ZFHX1A, Nil-2-a, TCF8, AREB6 or BZP, is a transcription factor belonging to the human ZEB family. Previous studies demonstrated that ZEB-1 serves a significant role in epithelial-to-mesenchymal transition (EMT) during tumor invasion and metastasis in various types of human cancer (7-9).

It has been reported that PD-L1 expression may be associated with ZEB-1 expression and poor prognosis in esophageal cancer since the gene promoter region of PD-L1 contains a binding site for ZEB-1, a transcription factor associated with EMT (10). Tsutsumi et al (10) also reported that small interfering RNA ZEB-1 suppressed PD-L1 expression through the ZEB-1/PD-L1 pathway and TGF- $\beta 1$-induced EMT in esophageal squamous cell carcinoma (ESCC) cell lines. 
Several studies have reported the individual association of PD-L1 and ZEB-1 with oral squamous cell carcinoma (OSCC) $(11,12)$. These reports indicated that both PD-L1 and ZEB-1 have the potential to be useful prognostic biomarkers in OSCC, individually, as they are in ESCC. However, to the best of our knowledge, the present study was the first to explore the association between the expression patterns of those two markers in patients with OSCC and clinicopathological characteristics or prognosis.

\section{Materials and methods}

Clinical characteristics of the patients. A total of 169 patients with OSCC initially visited Tokushima University Hospital (Tokushima, Japan) between April 2008 and March 2014 [including 92 men and 77 women (median age, 69.0 years; range, 24-97 years)] and were enrolled in the present study. All of the patients underwent radical surgery and were followed up after treatment (mean follow up period, 61 months; range, 3-132 months). The present study was a retrospective study and was approved by the Tokushima University Human Investigations Committee (approval no. 2516; Tokushima, Japan) and adhered to the principles in the Declaration of Helsinki. OSCC specimens were obtained by biopsy or surgery after the patients had provided informed consent. Clinical characteristics of the patients are presented in Table I. The primary tumor was located at sites including the tongue (71 sites), lower gingiva (46 sites), upper gingiva (26 sites), oral floor (13 sites), buccal mucosa (12 sites) and hard palate (one site). Oral cancer specimens were obtained during biopsy or surgery, and all patients were treated surgically. Tumor size and clinicopathological stage of OSCC were classified according to the 2002 TNM classification general rules (13) (all samples used in the present study were collected before the revision of TNM classification in 2017), and the numbers of T1, T2, T3 and T4 cases were $39,88,16$ and 26, respectively. The histological types of the obtained specimens were well-differentiated, moderately differentiated and poorly differentiated in 72, 90 and seven cases, respectively. Furthermore, in the present study, the Yamamoto-Kohama (YK) classification, a modified version of the classification proposed by Jakobsson et al (14) and Willén et al (15), was used to determine the pathological grade of tumor invasion (16). The number of cases classified under grades YK 1, YK 2, YK 3, YK 4C and YK 4D were 13, 41, 66, 30 and 14, respectively. In addition, unknown grade was assigned to five cases, as specimens of these cases were not collected deeply enough to clearly observe the tumor invasion front. In the present study, the tumor invasion front was defined as in a previous report, as the most progressed, with three to six tumor cell layers or detached tumor cell groups at the advancing edge of the histological specimen (17). Finally, the number of patients diagnosed with lymph node metastasis was counted, and 53 patients were diagnosed between the initial diagnosis and the end of the 5-year follow-up period.

Immunohistochemistry. The obtained specimens were fixed in neutral $10 \%$ formalin for $24 \mathrm{~h}$ at room temperature and embedded in paraffin after resection; $5-\mu \mathrm{m}$ sections were obtained and transferred onto slides. The sections were deparaffinized in xylene and dehydrated in graded ethanol. Standard hematoxylin and eosin (H\&E) staining was performed by the Department of Pathology, Tokushima University Hospital, at room temperature. Endogenous peroxidase activity was blocked using $3 \%$ hydrogen peroxide for $5 \mathrm{~min}$ at room temperature, and antigen retrieval using $10 \mathrm{mM}$ citrate buffer solution was performed in a microwave oven. Immunostaining was performed using an avidin-biotin-peroxidase enzyme complex (ABC kit; cat. no. PK4001; Vector Laboratories, Inc.). Briefly, the sections were incubated with monoclonal rabbit anti-human PD-L1 (dilution 1:1; clone SP142; cat. no. 518113193; Roche Diagnostics) and monoclonal rabbit anti-human ZEB-1 (dilution 1:100; clone EPR17375; cat. no. ab203829; Abcam) antibodies overnight at $4^{\circ} \mathrm{C}$, and subsequently incubated with secondary anti-rabbit antibody (ABC kit; cat. no. PK4001; Vector Laboratories, Inc.) for $30 \mathrm{~min}$ at room temperature followed by the avidin-biotin complex reagent. The sections were incubated in substrate 3,3-diaminobenzidine $(0.05 \%)$ for $20 \mathrm{~min}$ at room temperature and $0.1 \%$ hydrogen peroxide for $8 \mathrm{~min}$. The immunohistochemically stained images were observed using a light microscope (BX43; Olympus) in at least five fields of view, each at a different magnification (magnification, $x 40-400$ ). Thereafter, the percentage of tumor cells in the images was evaluated, and the specimens were graded as negative or positive for PD-L1 and ZEB-1. Briefly, expression of PD-L1 was considered as positive when $>1 \%$ of all tumor cells were stained (18), and ZEB-1 was considered as positive when $>10 \%$ of all tumor cells were stained (19). In the following sentences, positive results are indicated as (+), and negative results are indicated as (-). For example, PD-L1 (+)/ZEB-1 (-) indicates PD-L1-positive and ZEB-1-negative staining. Additionally, the expression patterns of PD-L1 and ZEB-1 were divided into four groups: Type A, PD-L1 (+)/ZEB-1 (+); Type B, PD-L1 (+)/ZEB-1 (-); Type C, PD-L1 (-)/ZEB-1 (+); Type D, PD-L1 (-)/ZEB-1 (-).

Statistical analyses. The $\chi^{2}$ test, Fisher's exact test, Kruskal-Wallis test, and Mann-Whitney U test were used to statistically analyze the relationship between the expression levels of PD-L1 and ZEB-1 and clinicopathological factors. Survival analysis was performed using the Kaplan-Meier method and compared using the log-rank test. A Cox hazard regression model was used for multivariate analysis. Analyses were performed using BellCurve for Excel (Social Survey Research Information Co., Ltd.). The results were quantified using hazard ratios (HRs) and $95 \%$ confidence intervals (CIs). $\mathrm{P}<0.05$ was considered to indicate a statistically significant difference.

\section{Results}

Expression of PD-L1 and ZEB-1 in OSCC. As shown in H\&E staining images (Fig. 1A and E), cancer cell nests with various size were observed. Representative staining images of PD-L1 and ZEB-1 proteins are shown in Fig. 1. The analysis revealed that PD-L1 protein was expressed in the cell membrane of cancer cells (Fig. 1B and C), whereas ZEB-1 protein was mainly observed in the intercellular substance and cell 
Table I. Clinicopathological characteristics of the patients.

\begin{tabular}{|c|c|c|}
\hline Characteristic & Group & $\begin{array}{c}\text { Number of } \\
\text { patients }\end{array}$ \\
\hline \multirow[t]{2}{*}{ Sex } & Male & 92 \\
\hline & Female & 77 \\
\hline \multirow[t]{6}{*}{ Primary site } & Tongue & 71 \\
\hline & Lower gingiva & 46 \\
\hline & Upper gingiva & 26 \\
\hline & Oral floor & 13 \\
\hline & Buccal mucosa & 12 \\
\hline & Hard palate & 1 \\
\hline \multirow[t]{4}{*}{$\mathrm{T}$ classification } & $\mathrm{T} 1$ & 39 \\
\hline & $\mathrm{T} 2$ & 88 \\
\hline & T3 & 16 \\
\hline & $\mathrm{T} 4$ & 26 \\
\hline \multirow{3}{*}{$\begin{array}{l}\text { Histological } \\
\text { differentiation }\end{array}$} & Well differentiated & 72 \\
\hline & Moderately differentiated & 90 \\
\hline & Poorly differentiated & 7 \\
\hline \multirow[t]{6}{*}{ YK classification } & YK 1 & 13 \\
\hline & YK 2 & 41 \\
\hline & YK 3 & 66 \\
\hline & YK 4C & 30 \\
\hline & YK 4D & 14 \\
\hline & Unknown & 5 \\
\hline \multirow[t]{2}{*}{ N status } & Negative & 116 \\
\hline & Positive & 53 \\
\hline
\end{tabular}

YK, Yamamoto-Kohama.

Table II. Expression rates of PD-L1 and ZEB-1.

\begin{tabular}{lcc}
\hline Marker & $\begin{array}{c}\text { Patients with positive } \\
\text { expression/total patients }\end{array}$ & Percentage $(\%)$ \\
\hline PD-L1 & $103 / 169$ & 60.9 \\
ZEB-1 & $48 / 169$ & 28.4
\end{tabular}

PD-L1, programmed cell death 1 ligand 1; ZEB-1, zinc finger E-box binding homeobox 1 .

membrane of cancer cells localized at the invasion front of the tumor (Fig. 1F and G).

The expression rates of PD-L1 and ZEB-1 in oral cancer tissues from 169 patients with OSCC are summarized in Table II. The positive rates of PD-L1 and ZEB-1 expression in patients with OSCC were $60.9 \%$ (103/169 patients) and $28.4 \%$ (48/169 patients), respectively.

Association of PD-L1 and ZEB-1 expression with clinicopathological characteristics. The statistical association between PD-L1 expression and clinicopathological features is demonstrated in Table III. PD-L1 expression was significantly associated with $\mathrm{YK}$ classification $(\mathrm{P}=0.02)$ and lymph node metastasis $(\mathrm{P}=0.02)$, although there was no statistical difference between PD-L1 expression and tumor size $(\mathrm{P}=0.97)$ or histological differentiation $(\mathrm{P}=0.64)$.

The association between ZEB-1 expression and clinicopathological features is presented in Table IV. Similar to PD-L1, ZEB-1 expression was significantly associated with $Y K$ classification $(\mathrm{P}=0.03)$ and lymph node metastasis $(\mathrm{P}<0.01)$. However, there was no association between ZEB-1 expression and tumor size $(\mathrm{P}=0.25)$ or histological differentiation $(\mathrm{P}=0.47)$.

The association of PD-L1 and ZEB-1 expression patterns with clinicopathological features is summarized in Table V. It should be noted that PD-L1 and ZEB-1 expression pattern was significantly associated with cervical lymph node metastasis. Cervical lymph node metastases were observed in $57.5 \%$ (23/40 patients) of Type A [PD-L1 (+)/ZEB-1 (+)] patients $(\mathrm{P}<0.01)$, whereas it was observed in $17.2 \%(10 / 58$ patients) Type D [PD-L1 (-)/ZEB-1 (-)] patients $(\mathrm{P}<0.01)$. These findings suggested that co-expression of PD-L1 and ZEB-1 was predominantly associated with the development of cervical metastases. With respect to the invasion mode (YK classification), the combination of Type A and D showed a $\mathrm{P}$-value near statistical significance $(\mathrm{P}=0.053)$ across all types, even though there was no statistical significance among all combinations. Briefly, Type A tended to exhibit a poor invasion mode (YK 4D), whereas Type D tended to show a clear border between tumor and normal tissue (YK 1). By contrast, tumor size ( $\mathrm{T}$ classification) and histological differentiation were not affected by PD-L1 and ZEB-1 expression.

Survival analysis. The survival rates of patients with OSCC with and without PD-L1 expression are demonstrated in Fig. 2. PD-L1 (+) patients had a 5-year survival rate of $88.2 \%$, whereas PD-L1 (-) patients were alive at the 5-year point. Briefly, PD-L1 expression was associated with a significantly worse prognosis for patients when compared with those without or with lower PD-L1 expression $(\mathrm{P}=0.0016)$.

The survival rates of patients with OSCC with and without ZEB-1 expression are revealed in Fig. 3. ZEB-1 (+) patients demonstrated a significantly lower survival rate when compared with ZEB-1 (-) patients; the 5-year survival rate was $77.6 \%$ in the ZEB-1 (+) group, whereas it was $99.0 \%$ in the ZEB-1 (-) group $(\mathrm{P}<0.001)$.

The combined effects of PD-L1 and ZEB-1 expression on the survival rate of patients with OSCC are summarized in Fig. 4. As shown, Type D and Type C patients demonstrated a $100 \%$ 5-year survival rate. The 5-year survival rate of Type B patients was $98.2 \%$. By contrast, Type A patients showed a significantly worse prognosis than the other groups, with a 5-year survival rate of $73.1 \%(\mathrm{P}<0.001)$ across all groups.

The results of a multivariate analysis of the factors associated with survival rate are shown in Table VI. The results indicated that $\mathrm{N}$ status (HR, 7.06; 95\% CI, 1.24-40.07; $\mathrm{P}=0.03$ ) and ZEB-1 expression (HR, 8.32; 95\% CI, 1.70-40.07; $\mathrm{P}=0.004$ ) were significantly associated with survival rate. Cox analysis for PD-L1 could not be performed since no deaths were reported in the PD-L1 (-) patient group in the present study. 
Table III. Statistical association between PD-L1 expression and clinicopathological features.

\begin{tabular}{|c|c|c|c|c|}
\hline Clinicopathological feature & Group & PD-L1 (+) $(n=103)$ & PD-L1 (-) $(\mathrm{n}=66)$ & P-value \\
\hline \multirow[t]{4}{*}{ T classification } & $\mathrm{T} 1$ & 25 & 14 & \multirow[t]{4}{*}{$0.97^{\mathrm{a}}$} \\
\hline & $\mathrm{T} 2$ & 52 & 36 & \\
\hline & $\mathrm{T} 3$ & 7 & 9 & \\
\hline & $\mathrm{T} 4$ & 19 & 7 & \\
\hline \multirow[t]{3}{*}{ Histological differentiation } & Well differentiated & 46 & 26 & \multirow[t]{3}{*}{$0.64^{\mathrm{a}}$} \\
\hline & Moderately differentiated & 53 & 37 & \\
\hline & Poorly differentiated & 4 & 3 & \\
\hline \multirow[t]{6}{*}{ YK classification } & YK 1 & 8 & 5 & \multirow[t]{6}{*}{$0.02^{\mathrm{a}}$} \\
\hline & YK 2 & 17 & 24 & \\
\hline & YK 3 & 45 & 21 & \\
\hline & YK 4C & 20 & 10 & \\
\hline & YK 4D & 10 & 4 & \\
\hline & YK unknown & 3 & 2 & \\
\hline \multirow[t]{2}{*}{$\mathrm{N}$ status } & Negative & 64 & 52 & \multirow[t]{2}{*}{$0.02^{\mathrm{b}}$} \\
\hline & Positive & 39 & 14 & \\
\hline
\end{tabular}

${ }^{\mathrm{a}}$ Mann-Whitney U test; ${ }^{\mathrm{b}} \chi^{2}$ test. PD-L1, programmed cell death 1 ligand 1; YK, Yamamoto-Kohama.
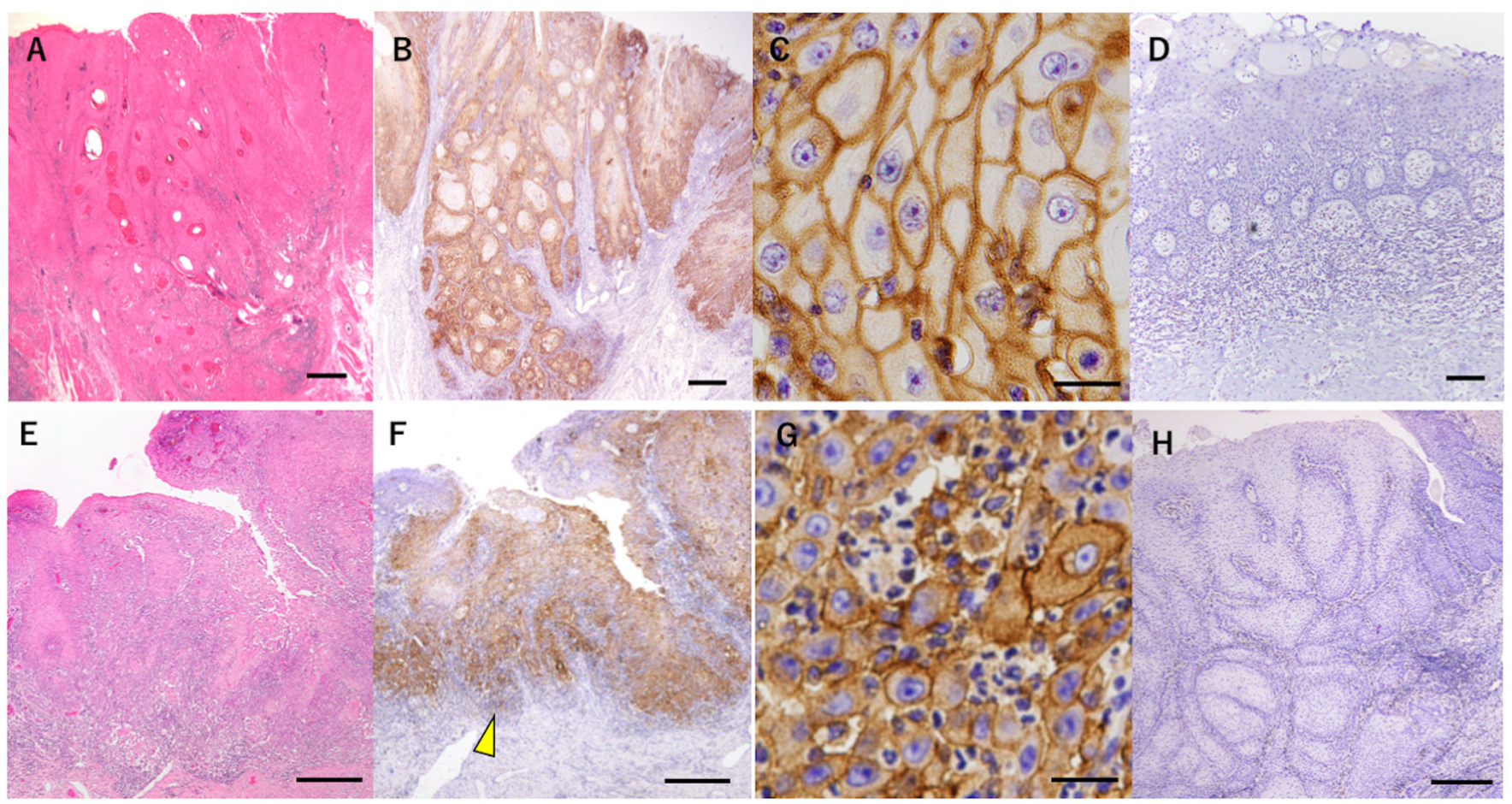

Figure 1. Typical histological images of oral squamous cell carcinoma tissues. (A and E) Routine H\&E staining. (B and C) Positive PD-L1 expression (low and high magnification). (D) Negative PD-L1 expression. (F and G) Positive ZEB-1 expression (low and high magnification). Yellow arrowhead indicates the tumor invasion front. (H) Negative ZEB-1 expression. A, B, D, E, F and H: Scale bar, $500 \mu \mathrm{m}$; C and G: Scale bar, $50 \mu \mathrm{m}$. PD-L1, programmed cell death 1 ligand 1; ZEB-1, zinc finger E-box binding homeobox 1.

\section{Discussion}

The results obtained in the present study demonstrated that both PD-L1 and ZEB-1 were associated with the invasion mode and lymph node metastasis of OSCC. Notably, co-expression of PD-L1 and ZEB-1 was strongly associated with higher cervical lymph node metastasis and a lower survival rate, even though it has been hypothesized that the survival rate may be biased since several cases were at the early stages of OSCC [T1: 39 cases and T2: 88 cases; Total: $127 / 169$ cases $(75 \%)]$ and inoperable cases were not included in the present study. 
Table IV. Statistical association between ZEB-1 expression and clinicopathological features.

\begin{tabular}{|c|c|c|c|c|}
\hline Clinicopathological feature & Group & ZEB-1 (+) (n=48) & ZEB-1 (-) (n=121) & P-value \\
\hline \multirow[t]{4}{*}{$\mathrm{T}$ classification } & $\mathrm{T} 1$ & 8 & 31 & $0.25^{\mathrm{a}}$ \\
\hline & $\mathrm{T} 2$ & 27 & 61 & \\
\hline & $\mathrm{T} 3$ & 3 & 13 & \\
\hline & $\mathrm{T} 4$ & 10 & 16 & \\
\hline \multirow[t]{3}{*}{ Histological differentiation } & Well differentiated & 19 & 53 & $0.47^{\mathrm{a}}$ \\
\hline & Moderately differentiated & 24 & 66 & \\
\hline & Poorly differentiated & 5 & 2 & \\
\hline \multirow[t]{6}{*}{ YK classification } & YK 1 & 1 & 12 & $0.03^{\mathrm{a}}$ \\
\hline & YK 2 & 9 & 32 & \\
\hline & YK 3 & 20 & 46 & \\
\hline & YK 4C & 12 & 18 & \\
\hline & YK 4D & 5 & 9 & \\
\hline & YK unknown & 1 & 4 & \\
\hline \multirow[t]{2}{*}{$\mathrm{N}$ status } & Negative & 21 & 95 & $<0.01^{\mathrm{b}}$ \\
\hline & Positive & 27 & 26 & \\
\hline
\end{tabular}

${ }^{\mathrm{a}}$ Mann-Whitney U test; ${ }^{\mathrm{b}} \chi^{2}$ test. ZEB-1, zinc finger E-box binding homeobox 1; YK, Yamamoto-Kohama.

Table V. Statistical association between PD-L1 and ZEB-1 expression and clinicopathological features.

\begin{tabular}{|c|c|c|c|c|c|c|}
\hline Clinicopathological feature & Group & $\begin{array}{l}\text { Type A } \\
(n=40)\end{array}$ & $\begin{array}{l}\text { Type B } \\
(n=63)\end{array}$ & $\begin{array}{c}\text { Type C } \\
(n=8)\end{array}$ & $\begin{array}{l}\text { Type D } \\
(n=58)\end{array}$ & $\mathrm{P}$-value \\
\hline \multirow[t]{4}{*}{ T classification } & $\mathrm{T} 1$ & 7 & 18 & 1 & 13 & NS \\
\hline & $\mathrm{T} 2$ & 22 & 30 & 5 & 31 & \\
\hline & $\mathrm{T} 3$ & 2 & 5 & 1 & 8 & \\
\hline & $\mathrm{T} 4$ & 9 & 10 & 1 & 6 & \\
\hline \multirow[t]{3}{*}{ Histological differentiation } & Well differentiated & 15 & 31 & 4 & 22 & NS \\
\hline & Moderately differentiated & 21 & 32 & 3 & 34 & \\
\hline & Poorly differentiated & 4 & 0 & 1 & 2 & \\
\hline \multirow[t]{6}{*}{ YK classification } & YK 1 & 1 & 7 & 0 & 5 & $0.053^{\mathrm{a}}$ \\
\hline & YK 2 & 6 & 11 & 3 & 21 & \\
\hline & YK 3 & 17 & 28 & 3 & 18 & \\
\hline & YK 4C & 11 & 9 & 1 & 9 & \\
\hline & YK 4D & 4 & 6 & 1 & 3 & \\
\hline & YK unknown & 1 & 2 & 0 & 2 & \\
\hline \multirow[t]{2}{*}{$\mathrm{N}$ status } & Negative & $17(42.5 \%)$ & $47(74.6 \%)$ & $4(50.0 \%)$ & $48(82.8 \%)$ & $<0.01^{\mathrm{b}}$ \\
\hline & Positive & $23(57.5 \%)$ & $16(25.4 \%)$ & $4(50.0 \%)$ & $10(17.2 \%)$ & \\
\hline
\end{tabular}

${ }^{a}$ Mann-Whitney U test; ${ }^{b} \chi^{2}$ test. Type A, PD-L1 (+) ZEB-1 (+); Type B, PD-L1 (+) ZEB-1 (-); Type C, PD-L1 (-) ZEB-1 (+); Type D, PD-L1 (-) ZEB-1 (-). NS, not significant; PD-L1, programmed cell death 1 ligand 1; ZEB-1, zinc finger E-box binding homeobox 1; YK, Yamamoto-Kohama.

PD-L1 expression has already been identified in several types of cancer, including head and neck cancer (20-28). In cancer, PD-L1 is expressed on the surface of tumor cells and non-transformed cells in the tumor microenvironment (2). PD-L1 is expressed on the plasma membrane of tumor cells and binds to PD-1 on the surface of activated T cells, inhibiting T-cell proliferation and activation. Inactivated $\mathrm{T}$ cells then remain in the tumor microenvironment without migrating, leading to tumor cells being resistant to host immunity (2). Certain studies have revealed that PD-L1 expression leads to worse outcomes $(25,29-31)$. For instance, Lin et al (11) reported that higher PD-L1 expression levels in OSCC were associated with several clinicopathological factors, such as female sex and distant metastases. Although there was no relationship between sex and PD-L1 expression in the present study, PD-L1 expression was associated with 


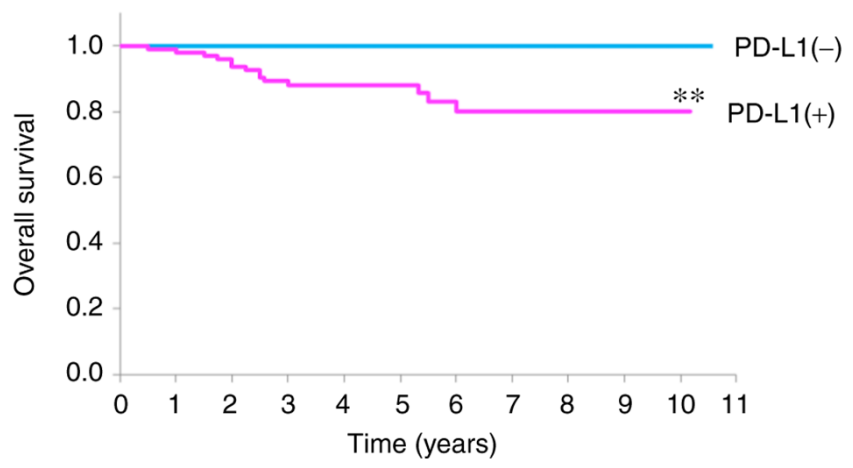

Figure 2. Overall survival curves according to PD-L1 expression. ${ }^{* *} \mathrm{P}<0.01$. PD-L1, programmed cell death 1 ligand 1.

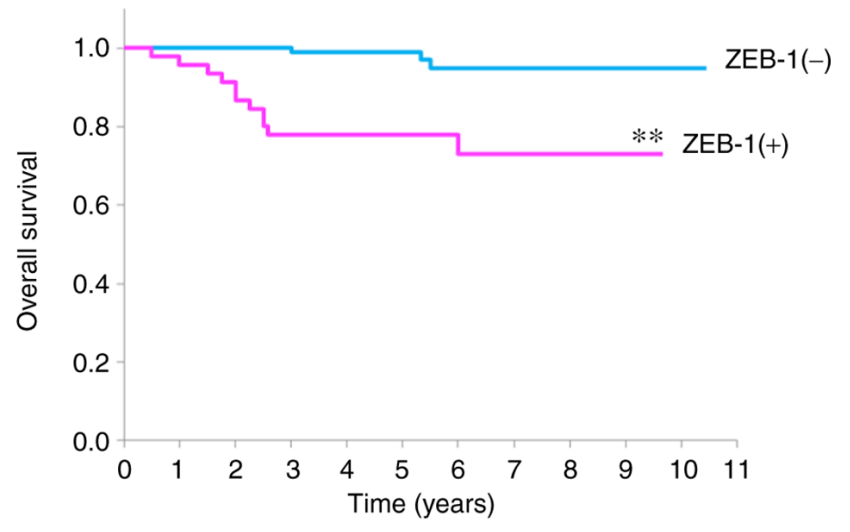

Figure 3. Overall survival curves according to ZEB-1 expression. ${ }^{* *} \mathrm{P}<0.01$. ZEB-1, zinc finger E-box binding homeobox 1.

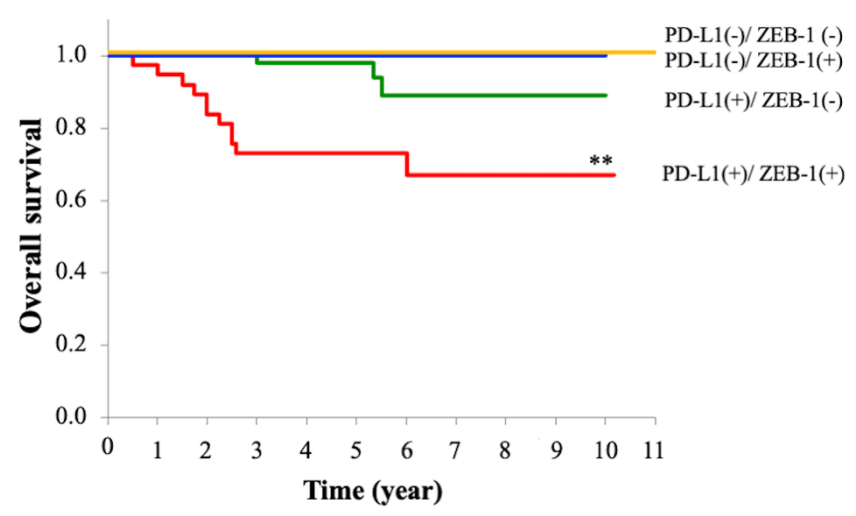

Figure 4. Overall survival curves according to PD-L1 and ZEB-1 expression. ${ }^{* *} \mathrm{P}<0.01$ across all four groups. PD-L1, programmed cell death 1 ligand 1; ZEB-1, zinc finger E-box binding homeobox 1.

not only invasion mode and high cervical metastases but also poor prognosis. As for the relationship between PD-L1 and tumor invasion, it has been suggested that PD-L1 expression may be involved in EMT via RAS/ERK signaling in a various types of carcinoma (32).

ZEB-1 is known as one of the transcription factors that are capable of downregulating E-cadherin expression. Yao et al (12) suggested that suppressed E-cadherin expression resulted in a worse prognosis due to increased OSCC migration
Table VI. Multivariate analysis of factors affecting overall survival in oral squamous cell carcinoma.

\begin{tabular}{lccc}
\hline Factor & HR & $95 \%$ CI & P-value \\
\hline Age & 1.00 & $0.95-1.05$ & 0.98 \\
T classification & 0.74 & $0.37-1.51$ & 0.41 \\
Histological type & 2.04 & $0.53-7.82$ & 0.29 \\
YK classification & 2.26 & $0.84-6.07$ & 0.11 \\
N status & 7.06 & $1.24-40.07$ & 0.03 \\
ZEB-1 & 8.32 & $1.70-40.07$ & 0.004 \\
\hline
\end{tabular}

ZEB-1, zinc finger E-box binding homeobox 1; YK, Yamamoto-Kohama.

and invasion, leading to metastasis. Tsutsumi et al (10) experimentally demonstrated that the expression of E-cadherin was upregulated when ZEB-1 was knocked down. Previous studies have reported that ZEB-1 overexpression is significantly associated with aggressive disease and poor clinical prognosis, including increased metastasis and post-treatment recurrence in other human malignancies, such as uterine cervical, breast and pancreatic cancer, and hepatocellular carcinoma $(11,12,25-36)$. Consistent with these findings, the ZEB-1 (+) group, which accounted for $28.4 \%$ of all patients with OSCC in the present study, showed a significantly worse type of YK classification and exhibited a significantly worse clinical outcome i.e., higher lymph node metastasis and lower overall survival rate.

In terms of the relationship between PD-L1 and ZEB-1, it has been hypothesized that ZEB-1 has a binding site in the promoter region of PD-L1. Tsutsumi et al (10) demonstrated using ESCC cell lines that PD-L1 mRNA and protein expression levels were suppressed upon ZEB-1 silencing mediated by small interfering RNA. These findings suggested that the ZEB-1 transcription factor may exist upstream of the PD-L1 signaling pathway, and ZEB-1 could be one of the regulation factors of PD-L1 expression, while simultaneously inducing EMT and evading the immune system, even though it has been hypothesized that other mechanisms may also affect the regulation of gene expression.

The present findings revealed that the co-expression pattern of PD-L1 and ZEB-1 led to poor prognosis in patients with OSCC, which could have been caused by EMT and the evasion of immune surveillance mechanisms. Briefly, this situation may have occurred since ZEB-1, an EMT-related factor, binds to the promoter region of the PD-L1 gene and regulates the expression of PD-L1, which is involved in EMT through RAS/ERK signaling. To confirm this hypothesis, it is necessary to collect more data on patients with OSCC, and to conduct further in vitro and in vivo experiments in future studies. Although it is a matter for speculation, PD-L1 and ZEB-1 could be useful prognostic markers for OSCC since the expression patterns can be examined by immunohistochemical staining without additional burden for the patients, such as a collection of tissue and blood samples.

In conclusion, PD-L1 and ZEB-1 expression was revealed to be associated with higher cervical lymph node metastasis 
and poor prognosis in OSCC. In particular, co-expression of PD-L1 and ZEB-1 was highly associated with poor prognosis in OSCC. Therefore, PD-L1 and ZEB-1 could serve as useful markers for predicting the prognosis of patients with OSCC and their clinical relevance should be explored further.

\section{Acknowledgements}

Not applicable.

\section{Funding}

The present study was supported by JSPS KAKENHI (grant no. 18K09745).

\section{Availability of data and materials}

The datasets used and/or analyzed during the current study are available from the corresponding author on reasonable request.

\section{Authors' contributions}

NT, NF and YM conceived and designed the study. NT, KA and KK analyzed and interpreted the data. NT and NF wrote, reviewed and revised the manuscript. NF and YM supervised the study. NT, NF, KA and KK confirm the authenticity of all the raw data. All authors have read and approved the final manuscript.

\section{Ethics approval and consent to participate}

The present study was approved by the Tokushima University Human Investigations Committee (approval no. 2516; Tokushima, Japan) and adhered to the principles in the Declaration of Helsinki. OSCC specimens were obtained by biopsy or surgery after the patients had provided informed consent.

\section{Patient consent for publication}

Not applicable.

\section{Competing interests}

The authors declare that they have no competing interests.

\section{References}

1. Ebrahimi A, Zhang WJ, Gao K and Clark JR: Nodal yield and survival in oral squamous cancer: Defining the standard of care. Cancer 117: 2917-2925, 2011.

2. Pardoll DM: The blockade of immune checkpoints in cancer immunotherapy. Nat Rev Cancer 22: 252-264, 2012.

3. Carlsson J, Sundqvist P, Kosuta V, Fält A, Giunchi F, Fiorentino M and Davidsson S: PD-L1 expression is associated with poor prognosis in renal cell carcinoma. Appl Immunohistochem Mol Morphol 28: 213-220, 2020.

4. Pei R, Zhang W, Wang S, Huang X and Zou Y: Prognostic value of PD-L1 in patients with hepatocellular carcinoma. Clin Lab: May 1 2019 (Epub ahead of print). doi: 10.7754/Clin.Lab.2018.180839.

5. Webb JR, Milne K, Kroeger DR and Nelson BH: PD-L1 expression is associated with tumor-infiltrating $\mathrm{T}$ cells and favorable prognosis in high-grade serous ovarian cancer. Gynecol Oncol 141: 293-302, 2016.
6. Takada K, Toyokawa G, Shoji F, Okamoto T and Maehara Y: The significance of the PD-L1 expression in non-small-cell lung cancer: Trenchant double swords as predictive and prognostic markers. Clin Lung Cancer 19: 120-129, 2018.

7. Gheldof A, Hulpiau P, van Roy F, De Craene B and Berx G: Evolutionary functional analysis and molecular regulation of the ZEB transcription factors. Cell Mol Life Sci 69: 2527-2541, 2012.

8. Vandewalle C, Van Roy F and Berx G: The role of the ZEB family of transcription factors in development and disease. Cell Mol Life Sci 66: 773-787, 2009.

9. Zhang PJ, Sun YT and Ma L: ZEB1: At the crossroads of epithelial-mesenchymal transition, metastasis and therapy resistance. Cell Cycle 14: 481-487, 2015.

10. Tsutsumi S, Saeki H, Nakashima Y, Ito S, Oki E, Morita M, Oda Y, Okano $\mathrm{S}$ and Maehara Y: Programmed death-ligand 1 expression at tumorinvasive front is associated with epithelial-mesenchymal transition and poor prognosis in esophageal squamous cell carcinoma. Cancer Sci 108: 1119-1127, 2017.

11. Lin YM, Sung WW, Hsieh MJ, Tsai SC, Lai HW, Yang SM, Shen KH, Chen MK, Lee H, Yeh KT and Chen CJ: High PD-L1 expression correlates with metastasis and poor prognosis in oral squamous cell carcinoma. PLoS One 10: e0142656, 2015.

12. Yao X, Sun S, Zhou X, Zhang Q, Guo W and Zhang L: Clinicopathological significance of ZEB-1 and E-cadherin proteins in patients with oral cavity squamous cell carcinoma. Onco Targets Ther 10: 781-790, 2017.

13. Sobin LH and Wittekind C: TNM Classification of Malignant Tumours. 6th edition. John Wiley \& Sons Inc., New York, USA, pp22-26, 2002.

14. Jakobsson PA, Eneroth CM, Killander D, Moberger G and Mårtensson B: Histologic classification and grading of malignancy in carcinoma of the larynx. Acta Radiol Ther Phys Biol 12: $1-8,1973$

15. Willén R, Nathanson A, Moberger G and Anneroth G: Squamous cell carcinoma of the gingiva. Histological classification and grading of malignancy. Acta Otolaryngol 79: 146-154, 1975

16. Yamamoto E, Miyakawa A and Kohama G: Mode of invasion and lymph node metastasis in squamous cell carcinoma of the oral cavity. Head Neck Surg 6: 938-947, 1984.

17. Piffko J, Bánkfalvi A, Ofner D, Rasch D, Joos U and Schmid KW: Standardized demonstration of silver-stained nucleolar organizer regions-associated proteins in archival oral squamous cell carcinomas and adjacent non-neoplastic mucosa. Mod Pathol 10: 98-104, 1997.

18. Burtness B, Harrington KJ, Greil R, Soulières D, Tahara M, de Castro G Jr, Psyrri A, Basté N, Neupane P, Bratland A, et al: Pembrolizumab alone or with chemotherapy versus cetuximab with chemotherapy for recurrent or metastatic squamous cell carcinoma of the head and neck (KEYNOTE-048): A randomised, open-label, phase 3 study. Lancet 394: 1915-1928, 2019.

19. Arumugam T, Ramachandran V, Fournier KF, Wang $H$, Marquis L, Abbruzzese JL, Gallick GE, Logsdon CD, McConkey DJ and Choi W: Epithelial to mesenchymal transition contributes to drug resistance in pancreatic cancer. Cancer Res 69: 5820-5828, 2009.

20. Chin D, Boyle GM, Williams RM, Ferguson K, Pandeya N, Pedley J, Campbell CM, Theile DR, Parsons PG and Coman WB: Novel markers for poor prognosis in head and neck cancer. Int J Cancer 113: 789-797, 2005.

21. Greaves P and Gribben JG: The role of B7 family molecules in hematologic malignancy. Blood 121: 734-744, 2013.

22. Keir ME, Liang SC, Guleria I, Latchman YE, Qipo A Albacker LA, Koulmanda M, Freeman GJ, Sayegh MH and Sharpe AH: Tissue expression of PD-L1 mediates peripheral T cell tolerance. J Exp Med 203: 883-895, 2006.

23. Azuma T, Yao S, Zhu G, Flies AS, Flies SJ and Chen L: B7-H1 is a ubiquitous antiapoptotic receptor on cancer cells. Blood 111: 3635-3643, 2008.

24. Konishi J, Yamazaki K, Azuma M, Kinoshita I, Dosaka-Akita H and Nishimura M: B7-H1 expression on non-small cell lung cancer cells and its relationship with tumor-infiltrating lymphocytes and their PD-1 expression. Clin Cancer Res 10: 5094-5100, 2004.

25. Ohigashi Y, Sho M, Yamada Y, Tsurui Y, Hamada K, Ikeda N, Mizuno T, Yoriki R, Kashizuka H, Yane K, et al: Clinical significance of programmed death-1 ligand-1 and programmed death-1 ligand-2 expression in human esophageal cancer. Clin Cancer Res 11: 2947-2953, 2005. 
26. Strome SE, Dong H, Tamura H, Voss SG, Flies DB, Tamada K, Salomao D, Cheville J, Hirano F, Lin W, et al: B7-H1 blockade augments adoptive T-cell immunotherapy for squamous cell carcinoma. Cancer Res 63: 6501-6505, 2003.

27. Thompson RH, Gillett MD, Cheville JC, Lohse CM, Dong H, Webster WS, Krejci KG, Lobo JR, Sengupta S, Chen L, et al: Costimulatory B7-H1 in renal cell carcinoma patients: Indicator of tumor aggressiveness and potential therapeutic target. Proc Natl Acad Sci USA 101: 17174-17179, 2004.

28. Wintterle S, Schreiner B, Mitsdoerffer M, Schneider D, Chen L, Meyermann R, Weller M and Wiendl H: Expression of the B7-related molecule B7-H1 by glioma cells: A potential mechanism of immune paralysis. Cancer Res 63: 7462-7467, 2003.

29. Ghebeh H, Mohammed S, Al-Omair A, Qattan A, Lehe C, Al-Qudaihi G, Elkum N, Alshabanah M, Bin Amer S, Tulbah A, et al: The B7-H1 (PD-L1) T lymphocyte-inhibitory molecule is expressed in breast cancer patients with infiltrating ductal carcinoma: Correlation with important high-risk prognostic factors. Neoplasia 8: 190-198, 2006.

30. Thompson RH, Kuntz SM, Leibovich BC, Dong H, Lohse CM, Webster WS, Sengupta S, Frank I, Parker AS, Zincke H, et al: Tumor B7-H1 is associated with poor prognosis in renal cell carcinoma patients with long-term follow-up. Cancer Res 66: 3381-3385, 2006.
31. Nomi T, Sho M, Akahori T, Hamada K, Kubo A, Kanehiro H, Nakamura S, Enomoto K, Yagita H, Azuma M and Nakajima Y: Clinical significance and therapeutic potential of the programmed death-1 ligand/programmed death-1 pathway in human pancreatic cancer. Clin Cancer Res 13: 2151-2157, 2007.

32. Zhang L, Xu LJ, Zhu J, Li J, Xue BX, Gao J, Sun CY, Zang YC, Zhou YB, Yang DR and Shan YX: ATM-JAK-PD-L1 signaling pathway inhibition decreases EMT and metastasis of androgen-independent prostate cancer. Mol Med Rep 17: 7045-7054, 2018.

33. Ran J, Lin DL, Wu RF, Chen QH, Huang HP, Qiu NX and Quan S: ZEB1 promotes epithelial-mesenchymal transition in cervical cancer metastasis. Fertil Steril 103: 1606-1614.e2, 2015.

34. Mock K, Preca BT, Brummer T, Brabletz S, Stemmler MP and Brabletz T: The EMT-activator ZEB1 induces bone metastasis associated genes including BMP-inhibitors. Oncotarget 6: 14399-14412, 2015

35. KuraharaH,Takao S,MaemuraK,Mataki Y,KuwahataT,MaedaK, Ding Q,Sakoda M,Iino S,Ishigami S, et al: Epithelial-mesenchymal transition and mesenchymal-epithelial transition via regulation of ZEB-1 and ZEB-2 expression in pancreatic cancer. J Surg Oncol 105: 655-661, 2012

36. Hashiguchi M, Ueno S, Sakoda M, Iino S, Hiwatashi K, Minami K, Ando K, Mataki Y, Maemura K, Shinchi H, et al: Clinical implication of ZEB-1 and E-cadherin expression in hepatocellular carcinoma (HCC). BMC Cancer 13: 572, 2013. 